\title{
A Comparative Study between the Therapeutic Role of Bone Marrow Mesenchymal Stem Cells and that of Histamine2 Receptor Antagonists (Nizatidine) in the Management of Ibuprofen Induced Gastric Ulcer in Adult Albino Rats
}

Osama F. Ahmed, Saadia A. Shalaby, Essam M. Ibraheem, Amal G. Metwally, Samia M. Manawy

Department of Anatomy and embryology, Benha faculty of medicine, Benha University, Egypt

Correspondence to: Amal G. Metwally, Department of Anatomy and embryolog, Benha faculty of medicine, Benha University, Egypt

Email:

dr_amal_gh@yahoo.com

Received: 16 July 2020

Accepted: 16 August 2020

\section{Abstract:}

Introduction: One of the widely used gastro protective agents are $\mathrm{H} 2$ receptor antagonists (H2RAs). But these drugs may induce several adverse effects. Recent studies have shown that mesenchymal stem cells (MSCs) play an important role in the healing of gut injuries. Aim of the work: To evaluate the role of bone marrow- mesenchymal stem cells (BM- MSCs) in the treatment of gastric ulcer, and to compare their efficacy with H2RAs therapy. Methods: 10 out of the 50 adult albino rats used in this study served as donors for stem cells and the other 40 rats were divided into four groups: Group I (control group). Group II (Gastric ulcer group), rats received $200 \mathrm{mg} / \mathrm{kg}$ ibuprofen suspended in CMC-Na $1 \%$ given orally by gastric tube. Group III (Nizatidine treated group), rats with gastric ulcer were treated with $31.25 \mathrm{mg} / \mathrm{kg}$ nizatidine, given orally by gastric tube. Group IV (BM-MSCs treated group), rats with gastric ulcer were injected with BMMSCs in the rat tail vein. Results: MSCs-treated group revealed improvement of histological structure and restoration of the normal architecture of the gastric mucosa. Nizatidine-treated group demonstrated nearly similar results to that of MSCs treated group. A significant decrease of tumor necrosis factor $\alpha$ (TNF- $\alpha)$ expression was observed in MSCs-treated group as well as nizatidine-treated group when compared to ulcer group $(P<0.01)$. Conclusion: MSCs could be a safer alternative therapy than H2RAs, with the benefit of avoiding the side effects of these drugs.

Key words: BMMSCs, gastric ulcer, H2RAs, TNF- $\alpha$. 


\section{Introduction:}

Peptic ulcer represents a serious medical problem because of its frequency among different socioeconomic classes. It affects around $10 \%$ of the world's population [1].

Ibuprofen, a strong analgesic and antiinflammatory drug, is used as the first line of treatment for rheumatoid arthritis and osteoarthritis. But similar to other nonsteroidal anti-inflammatory drugs (NSAIDS), the long term treatment of ibuprofen can lead to severe gastrointestinal side effects especially ulceration [2].

One of the most important factors in gastric damage induced by NSAIDS is suppression of prostaglandin (PG) production caused by inhibition of cox 1 and cox2 [3]. Diminished mucosal blood flow is also believed to be a major factor underlying the mechanism of NSAIDS induced gastric damage [4].

Several products have been introduced for treatment of peptic ulcer disease such as $\mathrm{H} 2$ receptor antagonists (H2 RAs) and proton pump inhibitors (PPIs), but they aren't completely effective and produce many adverse effects $[\mathbf{5 , 6 , 7 ]}$.

Mesenchymal stem cells (MSCs) provide a promising alternative approach for treating human diseases. They present in several types of tissues and organs as bone marrow, fat, muscles, lungs, liver, pancreas, and synovial membrane [8].

679
The interest in the stem cell based therapy for GIT injury has been growing recently. Several reports have indicated that bone marrow mesenchymal stem cells (BMMSCS) contribute to the formation of GIT tissues and play an important role in the healing of gut injuries [9].

\section{Materials and methods}

This experimental study was conducted on 50 adult albino rats of average weight $200 \mathrm{gm}$ - $250 \mathrm{gm}$, taken from and housed at the experimental animal unit of Kasr AlAiny Faculty of Medicine, Cairo University during a period of three months (from March 2019 to May 2019). All ethical rules for animal management were monitored. The experimental protocol was advised by the Institutional Animal Care Committee.

\section{Isolation and Labeling of MSCs:}

Bone marrow was collected by flushing femurs and tibiae of adult albino rats. Nucleated cells were isolated and suspended in complete culture medium supplemented with $1 \%$ penicillin streptomycin. Cells were incubated at $37 \mathrm{C}^{\circ}$ in $5 \%$ humidified $\mathrm{CO}_{2}$ for 12-14 days as primary culture or upon formation of large colonies. Culture was washed twice with phosphate buffered saline (PBS) and cells were trypsinized with $0.25 \%$ trypsin in $1 \mathrm{~m}$ M EDTA for $5 \mathrm{~min}$ at $37 \mathrm{C}^{\circ}$.After centrifugation, cells were 
suspended with serum supplemented medium and incubated in a $50 \mathrm{~cm} 2$ culture flask . The resulting cultures were referred as first passage cultures [10]. MSCs were labelled with the PKH26 fluorescent dye according to manufacturer protocol (Sigma Company, Saint Louis, Missouri USA), permitting tracing of the cells in tissues using fluorescence inverted microscope [11].

\section{Experimental design:}

Fifty adult albino rats were used in this study, 10 out of these rats served as donors for stem cells and the other 40 rats were divided into four groups. Each group consisted of 10 rats:

1) Group I (control group): subdivided into:

-Subgroup Ia (negative control group): no drugs received.

- Subgroup Ib (positive control group): They received sodium carboxy methyl cellulose 1\% (CMC-NA 1\%) solution by gastric tube for 6 days, then they were sacrificed.

\section{2) Group II (gastric ulcer group): They} fasted for 24 hours then induction of gastric ulcer was done by oral administration of $200 \mathrm{mg} / \mathrm{kg} /$ day ibuprofen (from Kahira pharmaceutical \& Chemical Company) by gastric tube [12]. After 6 consecutive days of treatment, rats were sacrificed.
3) Group III (Nizatidine treated group):

Rats were subjected to gastric ulceration as in group III, then they were treated with $31.25 \mathrm{mg} / \mathrm{kg}$ nizatidine (from Marcyrl chemical company), given orally by gastric tube once daily [2]. After 6 consecutive days of treatment, rats were sacrificed.

\section{4) Group IV (BMMSCS treated group):}

After ulcer induction, these rats were injected with single dose of $\left(3 \times 10^{(6)}\right.$ cells of BMMSCs) per rat by intravenous infusion at the rat tail vein [13]. One week after injection of MSCs, rats were sacrificed.

At the time of scarification, all rats were anesthetized, then the abdomen was opened by midline incision and the stomach was removed, examined macroscopically for mucosal lesions (ulcer index) then, the specimens were taken from the fundic stomach and prepared for histological and immunohistochemical staining.

Assessment of gastric mucosal lesion (ulcer index):

The gastric mucosal lesions were expressed in the term of ( ulcer index) which depends on the calculation of lesion index using a 0-3 scoring system based on the severity of each lesion. Severity factor $0=$ no lesion, $1=$ lesion $<1 \mathrm{~mm}$ in length, $2=$ lesion $2-4 \mathrm{~mm}$ in length and $3=$ lesion $>4 \mathrm{~mm}$ in length [14]. The length of gastric ulcer was measured with a vernier caliper. The lesions score for each rat was calculated 
as number of lesions in the rat multiplied by their respective severity factor.

\section{Light microscopic studies}

Stomach specimens were fixed in $10 \%$ formalin 48 hours. Paraffin sections $(5-\mu \mathrm{m}$ thick) were prepared, processed and stained with hematoxylin \& eosin (H\&E) to verify histological details [15].

\section{Immunohistochemical studies}

Immunohistochemical staining for detection of tumor necrosis factor alpha (TNF-a), was done. The primary monoclonal antibodies used were the mouse anti-TNF- $\alpha$ (Santa Cruz Biotechnology, Santa Cruz, California, USA) (1:300 with PBS). The cellular site of the reaction was the cytoplasm which appeared brown in color [16].

Immunohistochemical study was conducted using the avidin- biotin peroxidase method, followed by diaminobenzidine (DAB) (Dakopatts, Glostrup, Denmark) was added to slides as a chromogen. Thereafter, the slides were washed with distilled water. Later, the sections were counterstained with hematoxylin. For the negative control the specific primary antibody was substitute by phosphate buffered saline [17].

\section{Morphometric analysis:}

An image analyzer computer system was used to measure the area percentage of positive immunoreactivity for TNF- $\alpha$ (In immunolabeled sections) in 10 different non overlapping fields for each slide at $\times 200$ magnification $[18,16]$. Counting and image analysis were carried out in the Pathology department, Faculty of Medicine, Benha University using Leica Qwin 500 image analysis computer system (Leica Microsystems Ltd, Cambridge, UK).

\section{Statistical analysis}

Data were analyzed using IBM SPSS Statistics software for Windows, Version 20 (IBM Corp., Armonk, NY, USA).Student test was used to compare differences between each 2 groups. The data was evident as the mean $(\mathrm{M})$ value \pm standard deviation (SD).

\section{Results}

\section{-Gastric ulcer index (UI):}

In table 1 and graph 1 , the UI was highly significantly increased in ulcer group compared to the control group $(P<0.01)$.It was highly significantly decreased in Nizatidine group and in BM-MSC treated group compared to gastric ulcer group $(P<0.01)$. While the mean UI was significantly decreased in BM-MSC treated group compared to nizatidine treated group $(\mathrm{P}<0.05)$.

\section{- Histological study}

\section{Haematoxylin and eosin (H\&E) staining:}

Control group : Sections of the control rats showed normal architecture of the gastric fundic mucosa. It was 
composed of surface epithelium with gastric pits, lamina propria and muscularis mucosa. The gastric glands were divided into three regions: Isthmus, neck and the basal regions. Gastric glands lined with Parietal cells which appeared large spherical with central nucleus, mucous neck cells with foamy cytoplasm and Chief cells appeared as small cuboidal with basal basophilic cytoplasm (Figure 1).

Gastric ulcer group: This group showed various histological changes such as deep erosion in the gastric mucosa and marked damage of most of the cells. There were some exfoliated dead cells appearing in the lumen. The gastric gland cells showed marked vacuolation, degeneration. Infiltration of inflammatory cells and congested blood capillaries were observed. (Figure 2).

Nizatidine treated group: This group revealed improvement of histological structure and restoration of the normal architecture of the gastric mucosa. The surface epithelium restored its continuity with occasional shedded epithelium and mild focal areas of degeneration. Many gastric gland cells were intact, while others were vacuolated and degenerated. Diminished inflammatory cellular infiltrate was observed (Figure 3).
BM-MSCs treated group: Sections of this group showed cellular proliferation followed by complete restoration of surface epithelium of gastric mucosa with normal gastric pits. The gastric glands lined by intact parietal cells and chief cells. Reduced inflammatory cellular infiltrate and less congested blood capillaries were observed (Figure 4).

\section{-Immunohistochemical study}

\section{Immunohistochemical staining of TNF- $\alpha$ :}

Positive TNF- $\alpha$ immunohistochemical staining was demonstrated as brown cytoplasmic reaction (index for inflammation). The control groups showed very weak TNF- $\alpha$ immune expression. Ulcer Group showed highly positive expression of TNF- $\alpha$. Moderate expression of TNF- $\alpha$ was found in Nizatidine treated group, while there was weak expression of $\mathrm{TNF}-\alpha$ in BMMSCs treated group (Figure 5).

\section{Morphometric results}

As shown in table 2 and graph 2 : The mean area percentage of TNF- $\alpha$ immunostaining was highly significantly increased in ulcer group compared to control group $(\mathrm{P}<0.01)$. On the other hand, it was highly significantly decreased in Nizatidine treated group and BMMSCs treated group compared to ulcer group $(\mathrm{P}<0.01)$. While there was a significant decrease in the mean area percentage in BM-MSC treated group compared to nizatidine treated group ( $\mathrm{P}$ $<0.05)$. 
Table (1): showing the mean values of gastric ulcer index \pm SD with comparison between all groups.

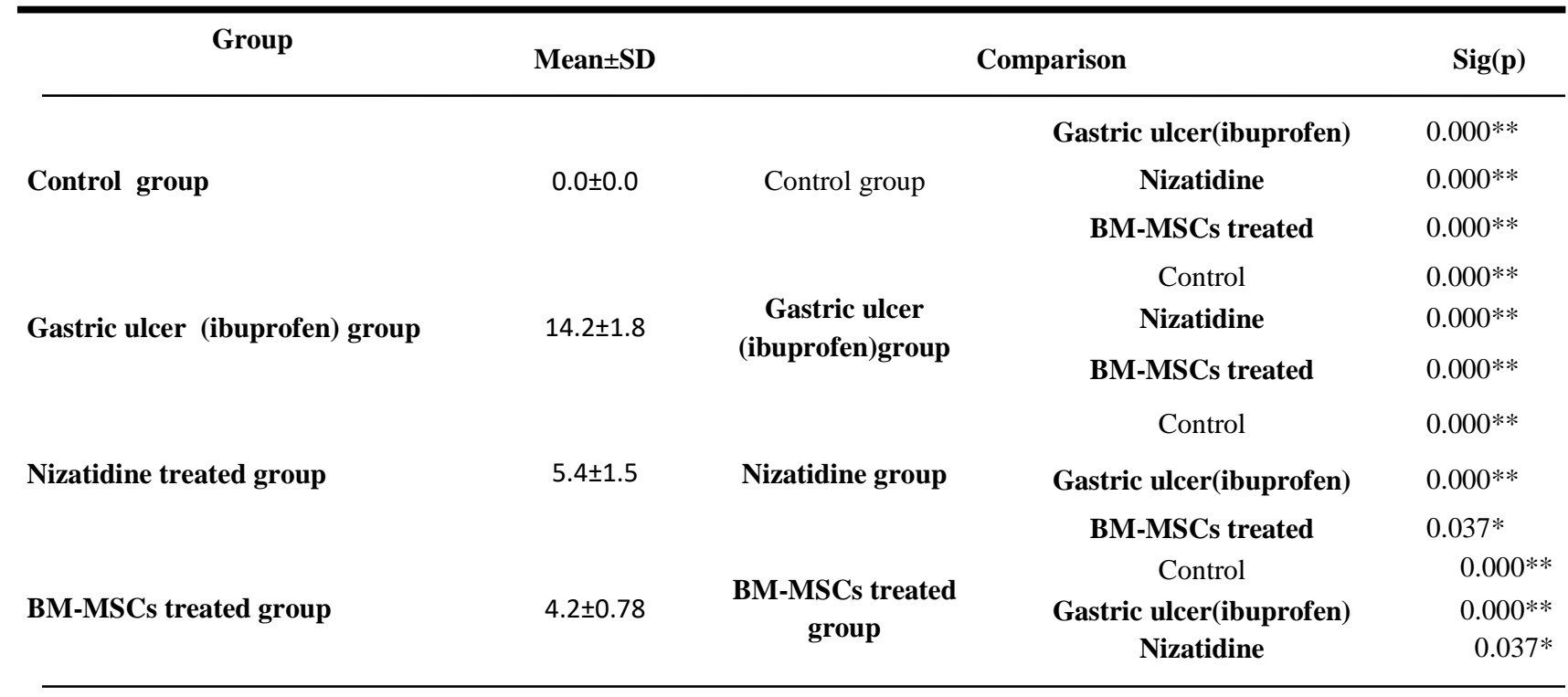

- $\quad P$ value $\geq 0.05$ means ( non- significant)

- P value $<0.05$ means ( significant)*

- P value $<0.01$ means ( highly significant) **

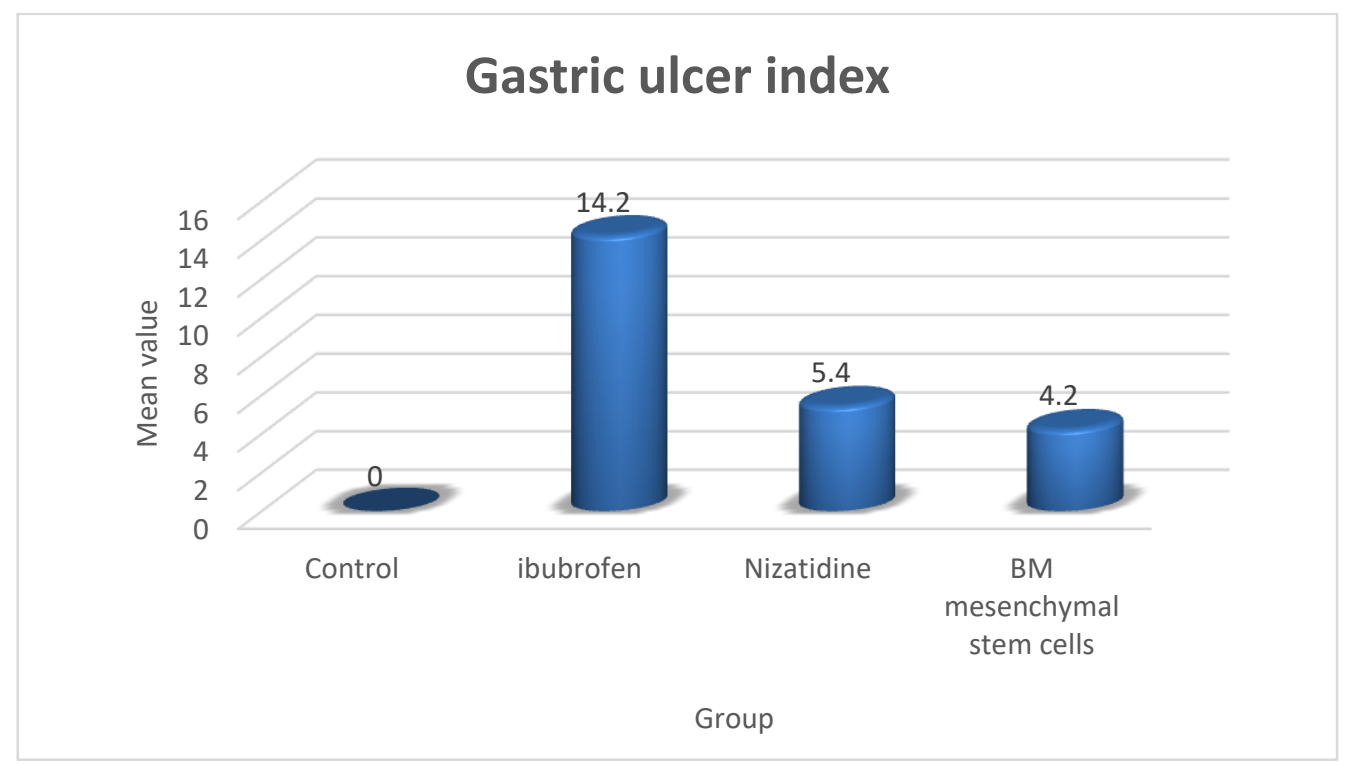

Graph (1): showing the mean values of gastric ulcer index (UI). 


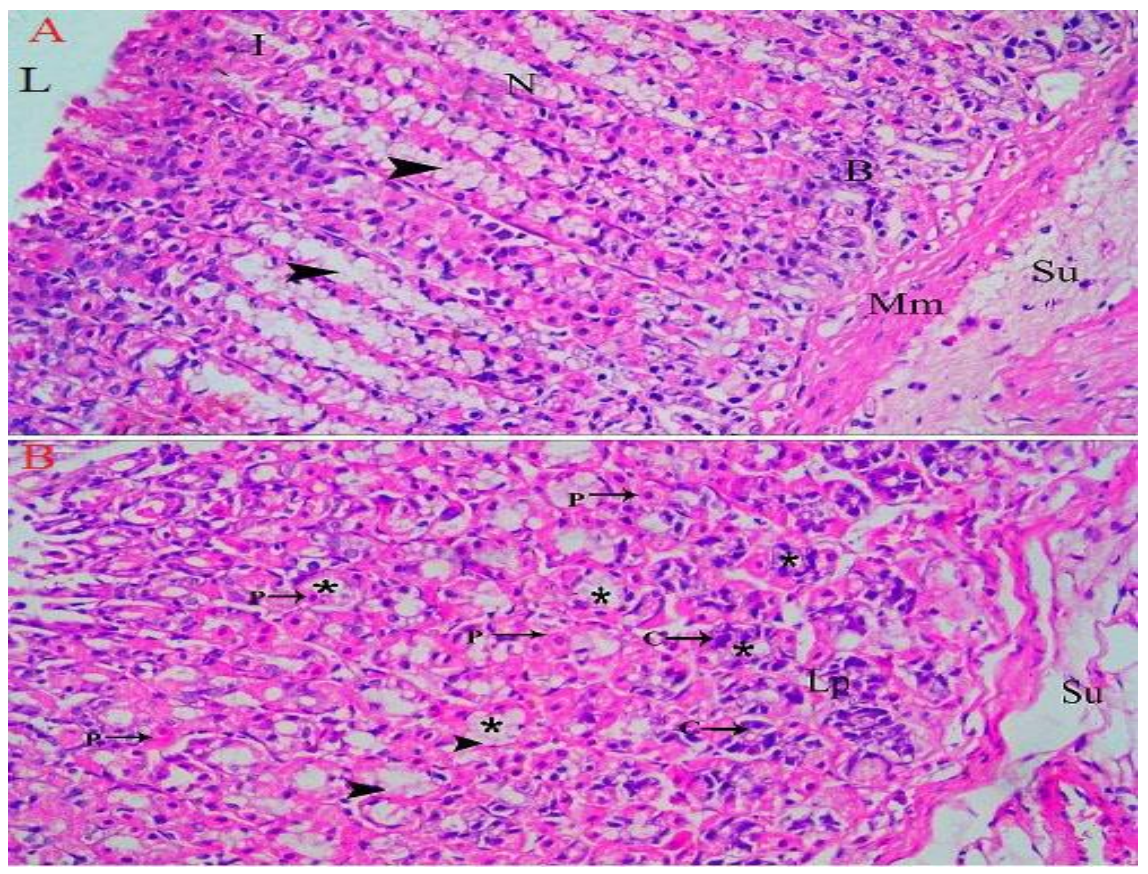

Fig. (1): A light photomicrograph of an adult control rat stomach showing : A- Normal gastric mucosa with the parts of the gastric glands: isthmus $(\mathrm{I})$, neck $(\mathrm{N})$, and base $(\mathrm{B})$. There are intact surface mucous cells (arrow head) .B-showing: Intact gastric glands $\left(^{*}\right)$ which are lined by large polyhedral parietal cells (P) and mucous neck cells (arrow head) while their bases are lined mainly with small cuboidal chief cells (C). Notice, lamina propria (Lp), the submucosa $(\mathrm{Su})$, the lumen of the stomach $(\mathrm{L})$, muscularis mucosa (Mm) .(H\&E $x$ 200)

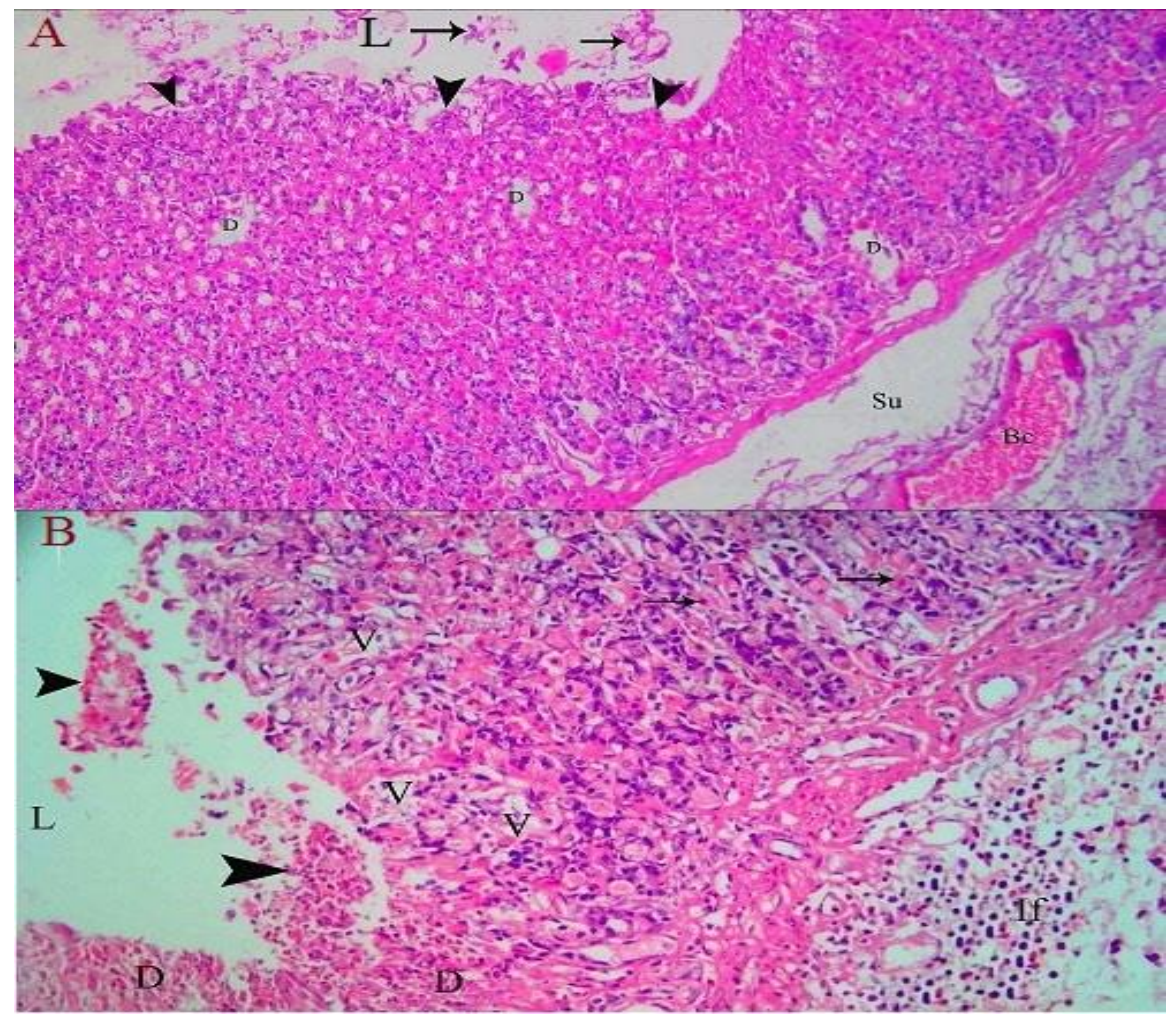

Fig. (2): A light photomicrograph of an adult rat stomach treated with ibuprofen : A- showing erosion in gastric mucosa (arrow heads) with presence of exfoliated dead cells (arrows) in the lumen of the stomach (L). There is focal areas of degeneration (D) in gastric mucosa and congested blood capillary (Bc) in the submucosa $(\mathrm{Su}) .(\boldsymbol{H} \& \boldsymbol{E} \mathbf{1 0 0})$ . $\boldsymbol{B}$ - showing presence of necrotic debris (arrow heads) in the lumen of the stomach (L).There is degeneration of gastric glands (D) and vacuolation of parietal cells (V). There is infiltration of inflammatory cells (If) in the submucosa ( $\mathrm{Su})$.Notice, some intact parietal cells (arrows) $(\boldsymbol{H} \& \boldsymbol{E} \boldsymbol{x} 200)$ 


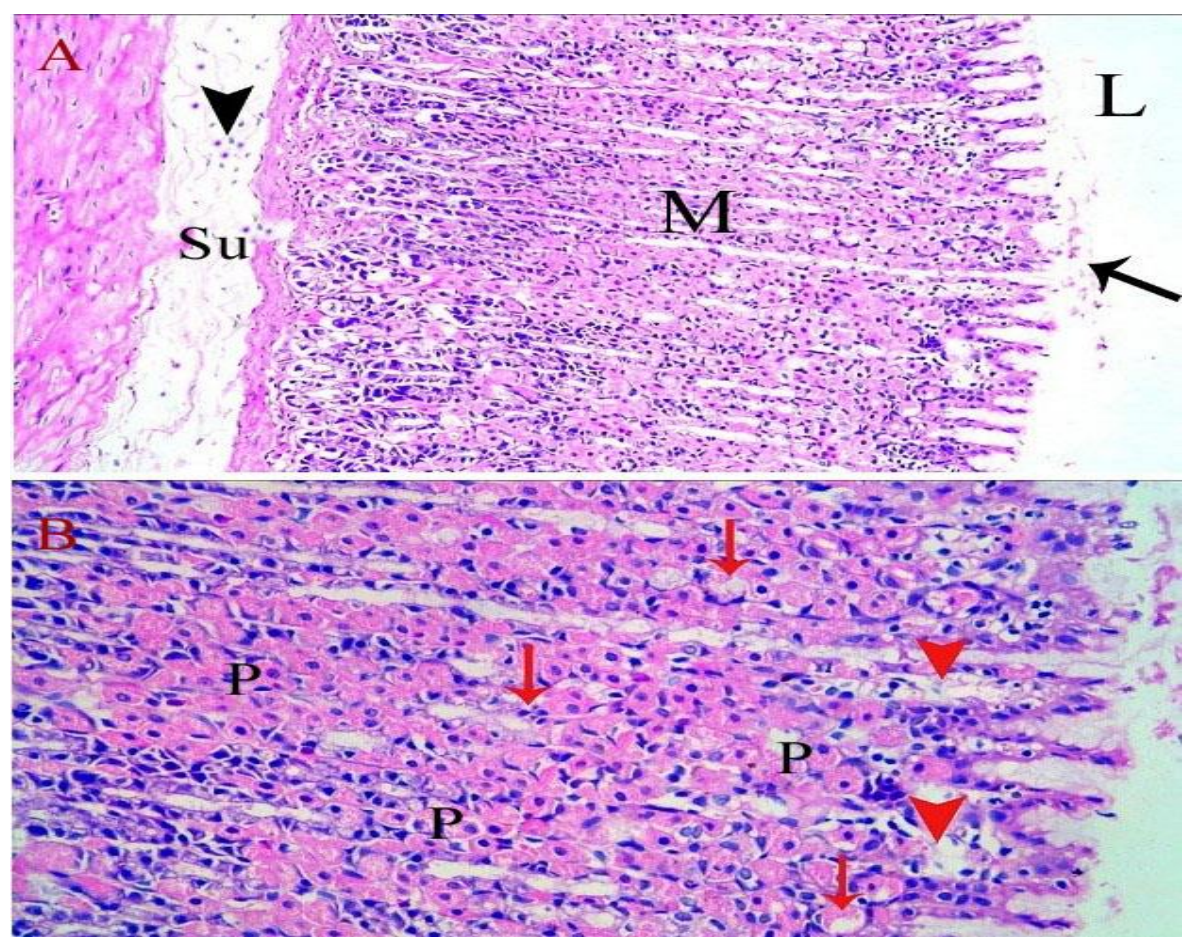

Fig. (3: A light photomicrograph of an adult rat stomach treated with nizatidine after ibuprofen :A- showing Improvement of the histological structure of the gastric mucosa (M). The surface epithelium shows occasional shedded epithelium (arrow) in the lumen of the stomach (L). Reduced inflammatory cellular infiltrate (arrow head) is observed in submucosa $(\mathrm{Su})(\boldsymbol{H} \boldsymbol{E} \boldsymbol{E} \boldsymbol{x 1 0 0})$.B- showing higher magnification of the same section with few areas of degeneration (arrow head), most of parietal cells are intact (p), while other cells are degenerated ( arrows) (H\&E 200).

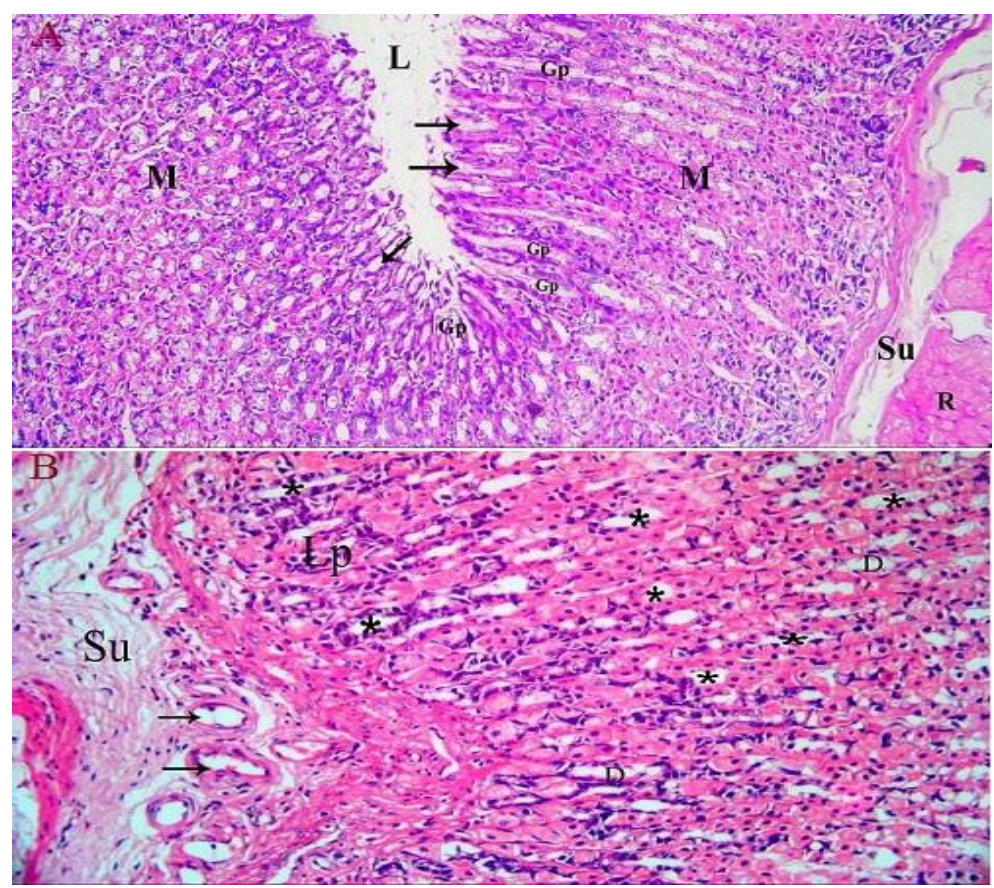

Fig. (4) : A light photomicrograph of an adult rat fundic stomach treated with BM-MSC after ibuprofen : Ashowing : complete restoration of gastric mucosa (M) with almost normal surface mucous cells (arrows) and gastric pits (GP). Notice: lumen of the stomach (L), submucosa (Su) and muscle layer (R) (H\&Ex 100$)$. B- showing: Intact gastric glands $\left(^{*}\right)$ which are lined with large intact parietal cells, while glands occupy the lamina propria (Lp) are lined mainly by chief cells . There is few distorted gastric glands (D).Intact blood capillaries (arrows) and reduced inflammatory cellular infiltrate are seen in submucosa $(\mathrm{Su})(\boldsymbol{H} \boldsymbol{E} \boldsymbol{E} \boldsymbol{x} 200)$. 


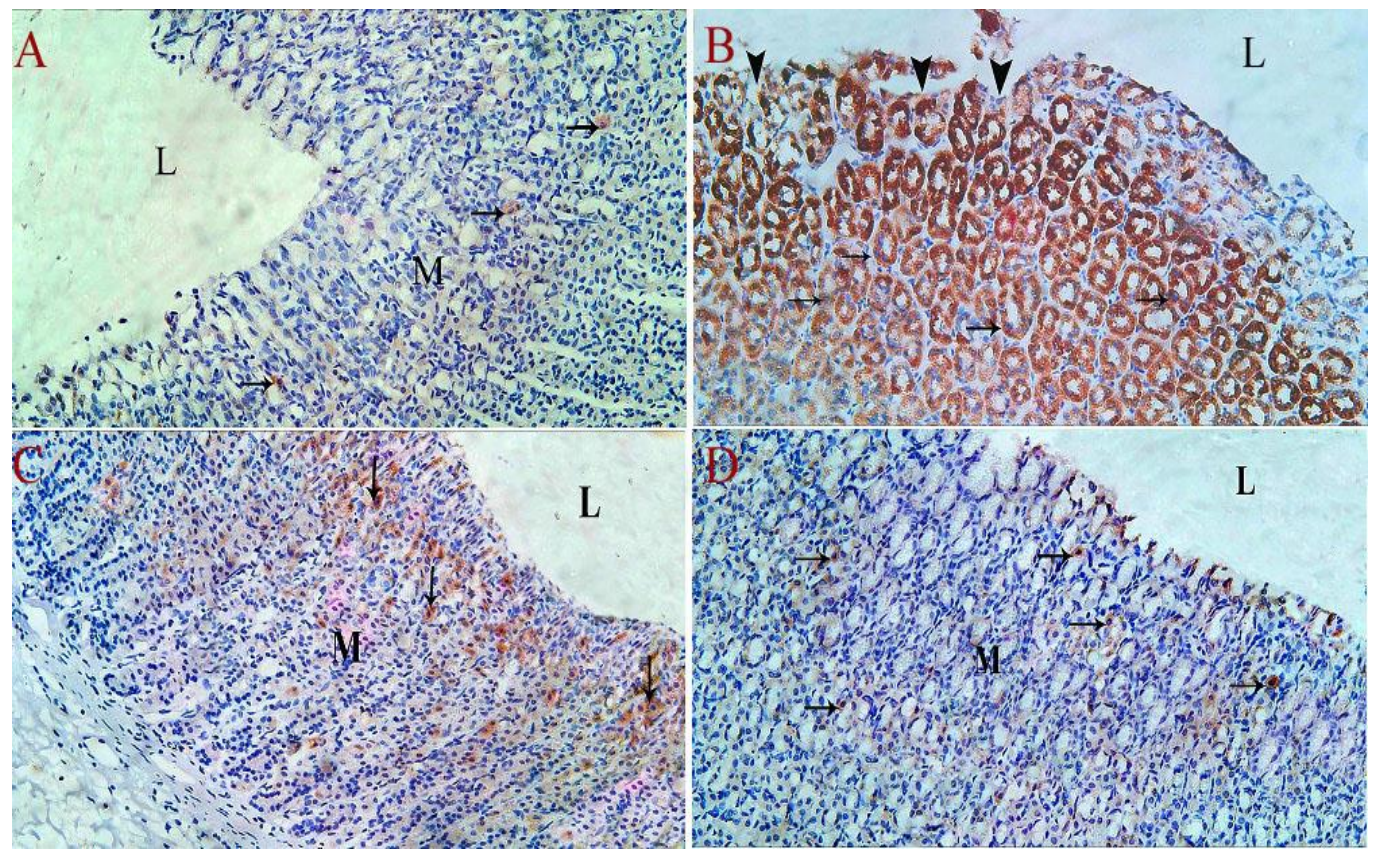

Fig. (5): A light photomicrograph of fundic mucosa: A-Group I: showing very weak TNF- $\alpha$ immunoreaction (brown cytoplasmic reaction of few parietal cells) (arrows) in the gastric mucosa (M) .B- Group II: showing highly positive TNF- $\alpha$ immunoreaction (arrows) with interruption of gastric mucosa (arrow heads). C- Group III: showing Moderate TNF- $\alpha$ immune expression (arrows) .D- Group IV: showing weak TNF- $\alpha$ immunoreaction (arrows) in gastric mucosa (M). Notice: the lumen of the stomach (L). (TNF- $\alpha \times 200)$

Table (2) : Showing the mean values of the area $\%$ of TNF $\alpha$ immunoreactivity \pm SD with comparison between all groups

\begin{tabular}{|c|c|c|c|c|}
\hline Group & Mean \pm SD & \multicolumn{2}{|c|}{ Comparison } & $\operatorname{Sig}(p)$ \\
\hline \multirow{3}{*}{ Control group } & \multirow{3}{*}{$1.99 \pm 0.69$} & \multirow{3}{*}{ Control group } & Gastric ulcer(ibuprofen) & $0.000 * *$ \\
\hline & & & Nizatidine & $0.000 * *$ \\
\hline & & & BM-MSCs treated & $0.000 * *$ \\
\hline \multirow{3}{*}{ Gastric ulcer (ibuprofen) group } & \multirow{3}{*}{$18.53 \pm 1.8$} & \multirow{3}{*}{$\begin{array}{c}\text { Gastric ulcer } \\
\text { (ibuprofen)group }\end{array}$} & Control & $0.000 * *$ \\
\hline & & & Nizatidine & $0.000 * *$ \\
\hline & & & BM-MSCs treated & $0.000 * *$ \\
\hline \multirow{3}{*}{ Nizatidine treated group } & \multirow{3}{*}{$7.5 \pm 1.1$} & \multirow{3}{*}{ Nizatidine group } & Control & $0.000 * *$ \\
\hline & & & Gastric ulcer(ibuprofen) & $0.000 * *$ \\
\hline & & & BM-MSCs treated & $0.024 *$ \\
\hline \multirow{3}{*}{ BM-MSCs treated group } & \multirow{3}{*}{$6.29 \pm 1.1$} & \multirow{3}{*}{$\begin{array}{c}\text { BM-MSCs treated } \\
\text { group }\end{array}$} & Control & $0.000 * *$ \\
\hline & & & Gastric ulcer(ibuprofen) & $0.000 * *$ \\
\hline & & & Nizatidine & $0.024 *$ \\
\hline
\end{tabular}




\section{Area \% of TNF $\alpha$ immunoreactivity}

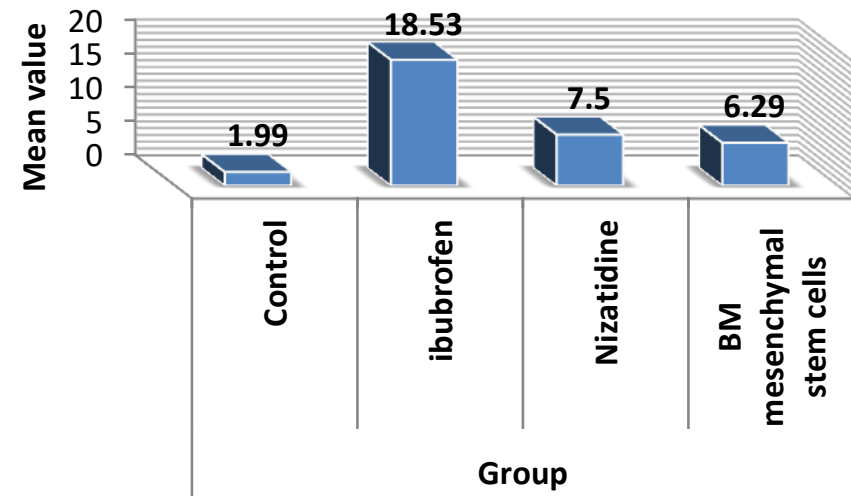

Graph (2): showing the mean values of the area \% of TNF $\alpha$ immunoreactivity.

\section{Discussion}

Gastric ulcer is the most widespread gastrointestinal tract disorders and gastric mucosa is recurrently exposed to several destructive and injurious factors [19].

In our work, the histological examination of $\mathrm{H} \& \mathrm{E}$ stained sections of group II revealed various histological changes as focal areas of degeneration and other areas of deep erosion in the gastric mucosa that may reach the muscularis mucosae and there were some exfoliated dead cells appearing in the lumen of the stomach. These results were in agreement with some researchers [2] who stated serious ulcers developed on the gastric mucosal surface after administration of ibuprofen. It is now well recognized that mucosal pro-inflammatory mediators such as tumor necrosis factor (TNF- $\alpha$ ), interleukin$1 \beta$ (IL-1 $\beta$ ) and platelet activating factor (PAF) are upregulated following NSAIDs (including ibuprofen) and are key mediators of the gastric injury. TNF- $\alpha$ stimulates caspase-3 in epithelial and endothelial cells of gastric mucosa and thus contributes to apoptosis and subsequent damage [20].

In the present study, immunohistochemical examination of group II showed highly positive expression of TNF- $\alpha$ in most of gastric gland cells. These findings were in harmony with some researchers [21] who stated that the level of TNF- $\alpha$ in gastric ulcer group was significantly increased compared to normal control group $(\mathrm{p}<0.05)$.

Previous researchers [2] reported that scavenging effects of $\mathrm{H} 2 \mathrm{RAs}$ on reactive oxygen species (ROS) through improving antioxidant enzyme activity which were important in protecting gastric ulcers induced by ibuprofen. Moreover, H2RAs were shown to reduce the bad effect of ibuprofen on gastric mucosa by reducing the HCL secretion, improve gastric blood flow 
and increase the synthesis of bicarbonate and cytoprotective prostaglandin [22].

According to our work results, nizatidine treated sections showed restoration of surface epithelium and glandular architecture .Parietal cells and chief cells revealed partial regeneration .These findings were in line with results published by some authors [23] who found that ulcerative stomach treated with H2RAs showing intact and healed gastric ulcer with no edema and mild leucocytes infiltration of the submucosal layer.

The mean area percentage of TNF- $\alpha$ immunostaining was statistically significantly decreased in nizatidine treated group compared with gastric ulcer group $(P<0.05)$.

While other investigators [24] reported statistical non-significant decrease in the level of TNF- $\alpha$ in H2RAS treated group compared to ethanol induced gastric ulcer group.

MSCs accelerate the healing of gastric ulcers by decreasing inflammation phase and stimulating of proliferative-reparation phase of the regeneration process. Moreover, MSCs reduced the liberation of inflammatory mediators and cytokines which minimized the damaging effect of inflammation $[25,26]$.
Our results revealed that BM-MSCs stimulate ulcer healing which was observed in the form of improvement of histological structure and restoration of the normal architecture of the gastric mucosa with almost normal gastric pits, intact mucous neck cells, the gastric glands lined by intact parietal cells and chief cells. These results were in line with some researchers $[\mathbf{2 7}, \mathbf{2 8}]$ who stated that BM-MSC treated rats showed minimal shedded epithelium with restoration of the normal architecture of the gastric mucosa.

In the present work, the histological examination of BM-MSC treated sections showed also reduced inflammatory cellular infiltrate and reduced congested blood capillaries. These findings were supported by weak TNF- $\alpha$ immunoreaction. The mean area percentage of TNF- $\alpha$ immunostaining was highly significantly decreased in BMMSC treated group compared with gastric ulcer group $(P<0.01)$. Similar findings were observed by other investigator [21].

So, our work results demonstrated that the role of stem cells is not restricted on migration to the site of gastric injury replacing the damaged one, but also their ability to decrease inflammatory mediators make them to have an evident efficacy in treating gastric ulcers. 


\section{Conclusion}

MSCs can ameliorate experimentallyinduced gastric ulcer in rats. Thus, they could be a safer alternative therapy than H2RAs.

\section{References}

1.Rao C.V. and Venkataramana K. (2013): A Pharmacological review on natural antiulcer agents. J Glob Trends Pharm Sci, 4:1118-31.

2. Liu J., Sun D., He J., Yang C., Hu T. , Zhang L. et al., (2016):Gastroprotective effects of several H2RAS on ibuprofen induced gastric ulcer in rats .Life sciences $; 149: 65-71$.

3. Takeuchi K. (2012): Pathogenesis of NSAIDinduced gastric damage: importance of cyclooxygenase inhibition and gastric hypermotility. World J Gastroenterol ; 18:2147-2160. 4. Santos C.L., Souza M.H., Gomes A.S., Lemos H.P., Santos A.A., Cunha F.Q. et al., (2005):Sildenafil prevents indomethacin -induced gastropathy in rats :role of leukocyte adherence and gastric blood flow .Br.J.Pharmacol.146;481-486.

5. Mcquaid K. (2007):Drugs used in the treatment of gastrointestinal disease .In Katzung BG, Masters SB, Trevor AJ. Basic and clinical pharmacology, $11^{\text {th }}$ ed. chapter 62 . McGraw Hill Professional ,USA .

6. Jianu C.S., Fossmark R., Viset T., Qvigstad G., Sørdal O., Mårvik R., et al. (2012): Gastric carcinoids after long-term use of a proton pump inhibitor. Aliment Pharmacol Ther, 36(7):644-9. Van Herwaarden N., Bos J.M., Veldman B. and Kramers C. (2016): Proton pump inhibitors: not as safe as they seem. Ned Tijdschr Geneeskd, 160:D487.
7. Sayed W.M. and Rashed L.A. (2016): Therapeutic role of bone marrow-derived mesenchymal stem cells in cyclophosphamide-induced cardiotoxicity in adult male albino rat: a morphological and immunohistochemical study. The Egyptian Journal of Histology;39: 281-293.

8. Liu L., Chiu P.W., Lam P.K., Poon C.C., Lam C.C. \& Lai P.B.S.(2015): Effect of local injection of mesenchymal stem cells on healing of sutured gastric perforation in an experimental model . Br J. Surg. 102(2):158-168

9.Zhang D., Liu X., Peng J., He D., Lin T., Zhu J., et al. (2014): Potential spermatogenesis recovery with bone marrow mesenchymal stem cells in an azoospermic rat model. International journal of molecular sciences, 15(8), 13151-13165.

10. Shao-Fang Z.I., Hong- Tian Z., Zhi-Nian Z., Yuan-Li H. (2011): PKH26 as a fluorescent lable for live human umbilical mesenchymal stem cells.In Vitro Cell Dev. Biol. Anim.47(8):516-520.

11. Fukushima E., Monoi N., Mikoshiba S., Hirayama Y., Serizawa T., Adachi, K. et al. (2014) : Protective effects of acetaminophen on ibuprofeninduced gastric mucosal damage in rats with associated suppression of matrix metalloproteinase. Journal of Pharmacology and Experimental Therapeutics, 349(1):165-173.

12. Lee D.H., Ahn Y., Kim S.U., Wang K.C., Phi J.H. \& Kim S.K. (2009):Targeting rat brainstem glioma using human neural stem cells and human mesenchymal stem cells .Clin. Cancer Res.15:49254943.

13. Peskar B.M., Ehrlich K., Peskar B.A. (2002):Role of ATP-sensetive potassium channels in 
14. prostaglandin-mediated gastroprotection in rat. $\mathrm{J}$ Pharmacol Exp. Ther 301:969-974.

15. Bancroft J.D. and Layton C. (2013):The hematoxylin and eosin, connective mesenchymal tissues with their stains In: Suvarna SK, Layton C and Bancroft JD, editors. Bancroft's Theory and practice of histological techniques. 7th edition. Churchill Livingstone: Philadelphia. 173-212 and 215-238.

16.El-Azab N. E., Mansy A. E., El-Mahalaway A. M., and Sabry D.(2018) : Comparative study of the therapeutic effect of pomegranate alone or in combination with bone marrow mesenchymal stem cells on experimentally induced gastric ulcer in adult male rats: A histological and immunohistochemical study.41(2) :150-166.

17. Cardiff R. D., Miller C. H., and Munn R. J. (2014) : Manual immunohistochemistry staining of mouse tissues using the avidin-biotin complex (ABC) technique. Cold Spring Harbor Protocols, (6), pdb-prot073429.

18. Soliman G. M., and Mostafa H. E. D. M. (2015) : Histological and immunohistochemical study of the effect of long period exposure to gold nanoparticles on the fundic mucosa of adult male albino rat. The Egyptian Journal of Histology, 38(1): 32-40.

19. Moghaddam G., Sharifzadeh M., Hassanzadeh G., Khanavi M. and Dolatshahi F. (2014) : Anti-ulcerative potential of Punica granatum $\mathrm{L}$ (Lythraceae) hydroalcohol fruit peel extract. Tropical Journal of Pharmaceutical Research ;13(7): 1093-1097.

20. Chauhan I., Agrawal S., and Goel R. K. (2018): Status of inflammatory markers and growth factor in gastric ulcer protective effects of Punica granatum L. peel extract in rat. National Journal of Physiology, Pharmacy and Pharmacology, 8(1), 12-17.

21.Rashed L., Gharib D. M., Hussein R. E., Tork O., \& Abusree, A. (2016) : Combined effect of bone marrow derived mesenchymal stem cells and nitric oxide inducer on injured gastric mucosa in a rat model. Tissue and Cell, 48(6), 644-652.

22. Suleyman H., Altinkaynak K., Gocer F., Maras A., Akcay F, Onyk M.D. and Gepdiremen A. (2002): effect of nimesulide on the indomethacin-and ibuprofeninduced ulcer in rat gastric tissue.Pol $\mathrm{J}$ Pharmacol.54:255-259.

23. Fahmi A. A., Abdur-Rahman M., Naser A. F. A., Hamed M. A., Abd-Alla H. I., Shalaby N. M. et al., (2019) : Chemical composition and protective role of Pulicaria undulata (L.) CA Mey. subsp. undulata against gastric ulcer induced by ethanol in rats. Heliyon, 5(3), e01359.

24. Talaat R. M., Abdel-Hakem N. E., and El-Toumy S. A. (2014): Anti-angiogenic and anti-inflammatory activity of punica granatum peel on experimentallyinduced gastric ulcer in rats. RJPBCS, 5(5), 42-56.

25. Askarov M.B. (2008): Multipotent mesenchymal stromal cells from autologous bone marrow accelerate regeneration of refractory gastric ulcers. Eksp Klin Gastroenterol; 4:52-4.

26.Lin Z.L., Zheng G.W., Zhang L., Zheng J.T. and Chen H. (2015): Effect of transplantation of BMMSCs on pathological change of gastric precancerous lesions of rats. Asian Pacific Journal of Tropical Medicine ;10: 1-4.

27. Youakim M. (2017) : Efficacy of mesenchymal stem cells in the treatment of gastric ulcers in rats : A histological andimmuno histochemical study . The Egyptian Journal of Anatomy, 40(1), 130-141.

28.Chang Q., Yan L., Wang C.Z., Zhang W.H., Hu Y.Z. and Wu B.Y. (2012): In vivo transplantation of bone marrow mesenchymal stem cells accelerates repair of injured gastric mucosa in rats Chinese Medical Journal, 125(6):1169-1174.

To cite this article: Osama F. Ahmed, Saadia A. Shalaby, Essam M. Ibraheem, Amal G. Metwally, Samia M. Manawy. A comparative study between the therapeutic role of bone marrow mesenchymal stem cells and that of histamine2 receptor antagonists (nizatidine) in the management of ibuprofen induced gastric ulcer in adult albino rats. BMFJ 2020; 37(3): 678-690 , DOI: 10.21608/bmfj.2020.36084.1288 